Federal Reserve Bank of Minneapolis Research Department

\title{
Sticky Prices and Sectoral Real Exchange Rates*
}

\author{
Patrick J. Kehoe and Virgiliu Midrigan \\ Working Paper 656
}

October 2007

\begin{abstract}
The classic explanation for the persistence and volatility of real exchange rates is that they are the result of nominal shocks in an economy with sticky goods prices. A key implication of this explanation is that if goods have differing degrees of price stickiness then relatively more sticky goods tend to have relatively more persistent and volatile good-level real exchange rates. Using panel data, we find only modest support for these key implications. The predictions of the theory for persistence have some modest support: in the data, the stickier is the price of a good the more persistent is its real exchange rate, but the theory predicts much more variation in persistence than is in the data. The predictions of the theory for volatiity fare less well: in the data, the stickier is the price of a good the smaller is its conditional variance while in the theory the opposite holds. We show that allowing for pricing complementarities leads to a modest improvement in the theory's predictions for persistence but little improvement in the theory's predictions for conditional variances.
\end{abstract}

*Kehoe, Federal Reserve Bank of Minneapolis, University of Minnesota, and National Bureau of Economic Research; Midrigan, Federal Reserve Bank of Minneapolis and New York University. We thank the National Science Foundation for research support. The views expressed herein are those of the authors and not necessarily those of the Federal Reserve Bank of Minneapolis or the Federal Reserve System. 
Perhaps the most widely studied price in international economics is the real exchange rate, defined as the relative price of two country's consumption baskets. It has been welldocumented that across a wide variety of countries that real exchange rates are volatile, persistent, and closely track the nominal exchange rate. (See, for example, Mussa 1986.) Accounting for these properties of real exchange rates using quantitative general equilibrium models is one of the main challenges in international economics.

The classic explanation for these properties is that they are the result of nominal shocks in an economy with sticky goods prices. For over four decades sticky prices have been at the heart of the most widely used models in international economics. The early static models were developed by Fleming (1962) and Mundell (1963), Dornbusch (1976) and Mussa (1982) added dynamics, and Svensson and van Wijnbergen (1989) and Obstfeld and Rogoff (1995) added the discipline of general equilibrium.

The main mechanism of the classic explanation is that persistent monetary shocks cause large persistent movements the nominal exchange rate, since nominal frictions impede good prices from moving quickly, the real exchange rate also exhibits large persistent movements. A key implication of this explanation is that the stickier are the nominal prices the more persistent are the resulting real exchange rates.

The idea of this paper is to develop and investigate a similar implication for the good level real exchange rates across countries: all else equal, the stickier are the prices for one type of good, the more persistent and more volatile will be the real exchange rate for that good. We begin by showing that this implication holds in commonly-used models of price stickiness extended to have the degree of price stickiness heterogeneous across goods. We then examine the data.

We find qualitative support for the predictions about persistence: stickier-priced goods tend to have more persistent real exchange rates. But at a quantitative level the discrepancy between the theory and the data is large. Since in the data, goods prices range from fairly flexible to fairly sticky, the theory predicts that these goods' real exchange rates should range 
from the fairly transient to the fairly persistent. In the data, however, almost all goods have persistent real exchange rates. In the raw data this pattern is driven by the fact that the real exchange rates of individual goods tends to closely track the nominal exchange rate pretty much regardless of the degree of price stickiness of those goods.

We find no evidence for the implication of the theory that stickier goods have real exchange rates with larger conditional variances. In the data we actually tend to see the opposite pattern: the conditional variances of the real exchange rate of stickier-priced goods tends to be smaller than that for more flexibly-priced goods.

We document our findings both for a simple theory and a more elaborate one that allows for extreme price complementarities (and, hence, extreme real rigidities) across goods.

We argue that our findings pose a major challenge to the classic explanation.

We begin with a benchmark two country model, referred to as the home and foreign country, with currencies referred to as dollars and euros, Calvo-type price stickiness, a heterogeneous price stickiness across a continuum of (composite) goods, and goods.For each good a continuum of brands is available. We refer to a good-brand pair as a commodity so that each good is a composite of a continuum of commodities. Each commodity is produced using labor by a monopolistically competitive firm that sets a dollar price in the home country and a euro price in the foreign country. All brands of a given good have the same degree of price stickiness, as measured by the infrequency of price adjustment, namely the probability that firms that produce that brand are not allowed to change their two home and foreign prices in a given period.

Consumers are standard and, for simplicity, have interest inelastic money demand. The money supplies in each country are such that the nominal exchange rate follows a random walk, a characteristic similar to that in the data. For a specification of utility along the lines of Hansen (1985) and Rogerson (1988), the relative price of a good has serial correlation equal to the infrequency of price adjustment of that good and a volatility proportional to that infrequency as well. In this sense, the simple model predicts that both persistence and 
volatility of the deviations from the law of one price have a one-for-one relationship with the degree of price stickiness. For more general specifications of utility a similar relationship holds.

We also extend the benchmark model to allow for pricing complementarities across goods of the type considered in Chari, Kehoe, and McGrattan (2000) and Woodford (2003). This extension tends to increase the persistence of the real exchange rate for the relatively less sticky goods by more than it does for the relatively more sticky goods. At both a qualitative and a quantitative level this extension brings the persistence predictions of the theory more in line with the data. This extension does little to help the theory in its predictions for conditional volatilities.

To investigate whether the predictions of the model are line with the patterns in the data for the U.S. and several European countries we use several sources of data. For the goodlevel real exchange rates, we use data on 66 product categories from harmonized consumer price indices across countries. In the appendix we also use the more aggregated 18 product category data that Imbs. et. al (2005) used in their study of the aggregation bias in real exchange rates as well. Both sets of data are derived from BLS and Eurostat data. For the degree of price stickiness across disaggregated product categories, referred to throughout as either goods or sectors, we use the results of several studies in which large datasets of price quotes collected at the level of individual outlets for the purpose of computing aggregate price indices that have been subsequently employed in order to calculate the frequency of price adjustment for disaggregated product-categories. For the U.S. we use the data from Bils and Klenow (2005). For Austria, Belgium, France, and Spain we, respectively, use the data from Baumgartner et. al (2005), Aucremanne and Dhyne (2004), Baudry et. al (2006), and Alvarez and Hernando (2004).

We argue that the classic mechanism for how sticky prices lead to persistent and volatile real exchange rates has, at best, modest support in the data and that the discrepancies between the theory and the data represent a major challenge for the theory. 


\section{A Benchmark Economy}

Consider a simple infinite horizon, cash-in-advance model with two countries: a home country and a foreign country. Each firm can price-discriminate across countries and must set prices in the currency of the local market. Once prices are set, each firm must satisfy the forthcoming demand. Firms reset prices as in Calvo (1983).

There are a continuum of goods, indexed $i \in[0,1]$. For each good a continuum of brands, indexed $z \in[0,1]$, is available. Each brand $z$ of a particular good $i$ is produced by one firm indexed $(i, z)$. We refer to each $(i, z)$ combination as a commodity. Brands $z$ for $z \leq 1 / 2$ are produced in the home country and brands $z>1 / 2$ are produced in the foreign country. Firm $(i, z)$ produces output $y_{i, z}\left(s^{t}\right)$ at $s^{t}$ using the technology

$$
y_{i, z}\left(s^{t}\right)=l_{i, z}\left(s^{t}\right)
$$

where $l_{i, z}\left(s^{t}\right)$.is the labor input and $s^{t}$ is the history of events $\left(s_{0}, \ldots, s_{t}\right)$ with probability distribution $\pi\left(s^{t}\right)$. A firm in the home country sells $c_{i, z}\left(s^{t}\right)$ to home consumers and $c_{i, z}^{*}\left(s^{t}\right)$ to foreign consumers and satisfies the resource constraint

(2) $\quad c_{i, z}\left(s^{t}\right)+(1+\tau) c_{i, z}^{*}\left(s^{t}\right)=y_{i, z}\left(s^{t}\right)$.

Here $\tau$ is an iceberg transport cost: if a firm ships $1+\tau$ units of commodity $(i, z)$ abroad, one unit arrives and the rest is used up in transport.

In this economy, the markets for state-contingent money claims are complete. We represent the asset structure by having complete, contingent, one-period nominal bonds denominated in the home currency. We let $B\left(s^{t}, s_{t+1}\right)$ denote the home consumers' holdings of such a bond purchased in period $t$ and state $s^{t}$ with payoffs contingent on some particular state $s_{t+1}$ at $t+1$. Let $B^{*}\left(s^{t}, s_{t+1}\right)$ denote the foreign consumers' holdings of this bond. One unit of this bond pays one unit of the home currency in period $t+1$ if the particular state $s_{t+1}$ occurs and 0 otherwise. Let $Q\left(s^{t+1} \mid s^{t}\right)$ denote the price of this bond in units of the home 
currency in period $t$ and state $s^{t}$. Clearly $Q\left(s^{t+1} \mid s^{t}\right)=Q\left(s^{t+1}\right) / Q\left(s^{t}\right)$. (Notice that also including bonds denominated in the foreign currency would be redundant.) For notational simplicity, we assume that claims to the ownership of firms in each country are held by the residents of that country and cannot be traded. We often refer to the home currency as dollars and the foreign currency as euros.

\section{Consumers}

Home consumers have utility functions defined over aggregate consumption $c\left(s^{t}\right)$ and labor supply $l\left(s^{t}\right)$ given by

(3) $\sum_{t=0}^{\infty} \sum_{s^{t}} \beta^{t} \pi\left(s^{t}\right) U\left(c\left(s^{t}\right), l\left(s^{t}\right)\right)$

Aggregate consumption $c\left(s^{t}\right)$ is a composite of consumption of each type of (composite) good $i$ given by

$$
c\left(s^{t}\right)=\left(\int_{0}^{1} c_{i}\left(s^{t}\right)^{\frac{\theta-1}{\theta}} d i\right)^{\frac{\theta}{\theta-1}}
$$

where $c_{i}\left(s^{t}\right)$, the consumption of good $i$, is itself a composite of each commodity $(i, z)$ given by

$$
c_{i}\left(s^{t}\right)=\left(\int_{0}^{1} c_{i, z}\left(s^{t}\right)^{\frac{\gamma-1}{\gamma}} d z\right)^{\frac{\gamma}{\gamma-1}} .
$$

Home consumers purchase all goods in the local currency and these purchases must satisfy the following cash-in-advance constraint:

$$
P\left(s^{t}\right) c\left(s^{t}\right) \leq M\left(s^{t}\right)
$$

where $M\left(s^{t}\right)$ is nominal money balances and $P\left(s^{t}\right)$ is the aggregate price level in the home 
country given by

$$
P\left(s^{t}\right)=\left(\int P_{i}\left(s^{t}\right)^{1-\theta} d i\right)^{\frac{1}{1-\theta}}
$$

Here $P_{i}\left(s^{t}\right)$ is the price of good $i$ given by

$$
P_{i}\left(s^{t}\right)=\left(\int P_{i, z}\left(s^{t}\right)^{1-\gamma} d z\right)^{\frac{1}{1-\gamma}}
$$

Home consumers face the sequence of asset market constraints expressed in units of the home country's currency

$M\left(s^{t}\right)+\sum_{s_{t+1}} Q\left(s^{t+1} \mid s^{t}\right) B\left(s^{t+1}\right)=R\left(s^{t-1}\right) W\left(s^{t-1}\right) l\left(s^{t-1}\right)+B\left(s^{t}\right)+\left[M\left(s^{t-1}\right)-p\left(s^{t-1}\right) c\left(s^{t-1}\right)\right]+T\left(s^{t}\right)$

where $R\left(s^{t}\right)$ is the uncontingent nominal interest rate define by $1 / R\left(s^{t}\right)=\sum_{s_{t+1}} Q\left(s^{t+1} \mid s^{t}\right)$. The left side of the budget constraint is the nominal value of assets held at the end of securities market trading. The first term on the right side is the payments the consumer receives from supplying labor. Consumers supply labor $l\left(s^{t-1}\right)$ in period $t-1$ and receive $R\left(s^{t-1}\right) W\left(s^{t-1}\right) l\left(s^{t-1}\right)$ units of local currency in the asset market in period $t$ where $W\left(s^{t-1}\right)$ is the nominal wage. Here we have the government paying interest on wages so that the consumer's first order condition for labor supply is undistorted. The second term on the right side of the budget constraint is the value of nominal debt bought in the preceding period. The term in brackets is the shopper's unspent cash and the final term, $T\left(s^{t}\right)$, is nominal transfers.

We will assume that the holdings of real debt $B\left(s^{t}\right) / p\left(s^{t}\right)$ are bounded above and below by some arbitrarily large constants.

Note, for later use, that the first order condition for labor supply is

(6) $-\frac{U_{l}\left(s^{t}\right)}{U_{c}\left(s^{t}\right)}=\frac{W\left(s^{t}\right)}{P\left(s^{t}\right)}$ 
while the first order condition for dollar bonds

$$
Q\left(s^{t+1} \mid s^{t}\right)=\beta \pi\left(s^{t+1} \mid s^{t}\right) \frac{U_{c}\left(s^{t+1}\right)}{P\left(s^{t+1}\right)} \frac{P\left(s^{t}\right)}{U_{c}\left(s^{t}\right)}
$$

The problem of the foreign consumer is analogous and we denote foreign variables with an asterisk. In particular note that the foreign consumer's first order conditions for labor supply and bonds are

$$
-\frac{U_{l}^{*}\left(s^{t}\right)}{U_{c}^{*}\left(s^{t}\right)}=\frac{W^{*}\left(s^{t}\right)}{P^{*}\left(s^{t}\right)}
$$

and

$$
Q\left(s^{t+1} \mid s^{t}\right)=\beta \pi\left(s^{t+1} \mid s^{t}\right) \frac{U_{c}^{*}\left(s^{t+1}\right)}{E\left(s^{t+1}\right) P^{*}\left(s^{t+1}\right)} \frac{E\left(s^{t}\right) P^{*}\left(s^{t}\right)}{U_{c}^{*}\left(s^{t}\right)}
$$

while the price of good $i$ in the foreign country in euros is

$$
P_{i}^{*}\left(s^{t}\right)=\left(\int P_{i, z}^{*}\left(s^{t}\right)^{1-\gamma} d z\right)^{\frac{1}{1-\gamma}} .
$$

\section{Firms}

Each firm $(i, z)$ sets a dollar price $P_{i, z}\left(s^{t}\right)$ for its commodity in the home country and a euro price $P_{i, z}^{*}\left(s^{t}\right)$ for its commodity in the foreign country. Not all firms adjust prices every period. Rather, the probability that a firm that produces good $i$ does not adjust in a particular period is $\lambda_{i}$. We refer to $\lambda_{i}$ as the infrequency of price adjustment. This probability is, as in the Calvo (1983) setup, an exogenously imposed constant. All home firms that produce brand $z$ of good $i$, namely $\left\{(i, z) \mid z \in[0,1 / 2\}\right.$, and adjust at $s^{t}$ set the same price in the home market denoted $P_{H i}\left(s^{t}\right)$ and the same price in the foreign market denoted $P_{H i}^{*}\left(s^{t}\right)$. The 
problem of such a firm in the home market is

$$
\max _{\left.P_{H i}\left(s^{t}\right)\right)} \sum_{r=t}^{\infty} \sum_{s^{r}} \lambda_{i}^{r-t} Q\left(s^{r} \mid s^{t}\right)\left[P_{H i}\left(s^{t}\right) c_{H i}\left(s^{r}\right)-W\left(s^{r}\right) c_{H i}\left(s^{r}\right)\right]
$$

subject to

$$
c_{H i}\left(s^{r}\right)=\left(\frac{P_{H i}\left(s^{t}\right)}{P_{i}\left(s^{r}\right)}\right)^{-\gamma} c_{i}\left(s^{r}\right)
$$

All foreign firms that produce brand $z$ of good $i$, namely $\{(i, z) \mid z \in[1 / 2,1\}$, and adjust at $s^{t}$ set the same price in the home market denoted $P_{F i}\left(s^{t}\right)$ and the same price in the foreign market denoted $P_{F i}^{*}\left(s^{t}\right)$. The problem of such a firm in the home market is

$$
\max _{P_{F i}\left(s^{t}\right)} \sum_{r=t}^{\infty} \sum_{s^{r}} \lambda_{i}^{r-t} Q\left(s^{r} \mid s^{t}\right)\left[P_{F i}\left(s^{t}\right) c_{F i}\left(s^{r}\right)-(1+\tau) E\left(s^{r}\right) W^{*}\left(s^{r}\right) c_{F i}\left(s^{r}\right)\right]
$$

subject to

$$
c_{F i}\left(s^{r}\right)=\left(\frac{P_{F i}\left(s^{t}\right)}{P_{i}\left(s^{r}\right)}\right)^{-\theta} c_{i}\left(s^{r}\right),
$$

where $E\left(s^{t}\right)$ is the nominal exchange rate. We assume that each firm has the exclusive right to sell their own goods in the two countries. Thus, price differences in goods across countries cannot be arbitraged away.

\section{Equilibrium}

We assume that the growth rate of the home money supply $\mu\left(s^{t}\right)=M\left(s^{t}\right) / M\left(s^{t-1}\right)$ follows the exogenous stochastic process

$$
\log \mu\left(s^{t}\right)=\rho_{\mu} \log \mu\left(s^{t-1}\right)+\varepsilon_{\mu}\left(s^{t}\right)
$$

where $\varepsilon_{\mu}\left(s^{t}\right)$ is a normally distributed i.i.d. random variable with mean zero and variance $\sigma_{\mu}^{2}$. Home money injections are made with lump sum transfers to consumers in the home country 
of $M\left(s^{t}\right)-M\left(s^{t-1}\right)$ while interest payments on wages are collected as lump sum taxes of $\left(R\left(s^{t-1}\right)-1\right) W\left(s^{t-1}\right) l\left(s^{t-1}\right)$. Hence, total transfers to consumers are

$$
T\left(s^{t}\right)=M\left(s^{t}\right)-M\left(s^{t-1}\right)-\left[\left(R\left(s^{t-1}\right)-1\right) W\left(s^{t-1}\right) l\left(s^{t-1}\right)\right]
$$

The growth rate of the foreign money supply follows a symmetric process and foreign transfers are made in a similar manner.

The resource constraints for labor for the home and foreign countries are

$$
l\left(s^{t}\right)=\int_{i} \int_{z=0}^{1 / 2} l_{i, z}\left(s^{t}\right) d i d z
$$

and

$$
l^{*}\left(s^{t}\right)=\int_{i} \int_{z=1 / 2}^{1} l_{i, z}\left(s^{t}\right) d i d z .
$$

The market-clearing condition for contingent bonds is $B\left(s^{t}\right)+B^{*}\left(s^{t}\right)=0$.

An equilibrium for this economy is a collection of allocations for consumers $\left\{c_{i, z}\left(s^{t}\right)\right\}_{i, z}$, $M\left(s^{t}\right), B\left(s^{t+1}\right)$ and $l\left(s^{t}\right)$; allocations for foreign consumers $\left\{c_{i, z}^{*}\left(s^{t}\right)\right\}_{i, z}, M^{*}\left(s^{t}\right), B^{*}\left(s^{t+1}\right)$ and $l^{*}\left(s^{t}\right), B^{*}\left(s^{t+1}\right)$; allocations and prices for home firms $\left\{P_{i, z}\left(s^{t}\right), P_{i, z}^{*}\left(s^{t}\right), l_{i, z}\left(s^{t}\right), y_{i, z}\left(s^{t}\right)\right\}_{i, z \leq 1 / 2}$; allocations and prices for foreign firms

$\left\{p_{i, z}\left(s^{t}\right), p_{i, z}^{*}\left(s^{t}\right), l_{i, z}\left(s^{t}\right), y_{i, z}\left(s^{t}\right)\right\}_{i, z>1 / 2}$;nominal wages $W\left(s^{t}\right), W^{*}\left(s^{t}\right)$, and bond prices $Q\left(s^{t+1} \mid s^{t}\right)$ that satisfy the following four conditions: $(i)$ the consumer allocations solve the consumers' problem; (ii) the prices and allocations of firms solve their maximization problem; (iii) the market-clearing conditions hold; (iv) the money supply processes and transfers satisfy the specifications above.

Given this equilibrium we can define the real exchange rate

$$
q\left(s^{t}\right)=\frac{E\left(s^{t}\right) P^{*}\left(s^{t}\right)}{P\left(s^{t}\right)}
$$


as the ratio of the aggregate prices in the home and foreign countries, expressed in the home currency. From (7) and (9) we can derive

$$
q\left(s^{t}\right)=\kappa \frac{U_{c}^{*}\left(s^{t}\right)}{U_{c}\left(s^{t}\right)}
$$

where $\kappa=q\left(s^{0}\right) U_{c}\left(s^{0}\right) / U_{c}^{*}\left(s^{0}\right)$. We can likewise define the relative price of good $i$ in the home and foreign countries as

$$
q_{i}\left(s^{t}\right)=\frac{E\left(s^{t}\right) P_{i}^{*}\left(s^{t}\right)}{P_{i}\left(s^{t}\right)}
$$

We are interested in a stationary equilibrium and we have restricted the stochastic processes for firm-specific shocks and money growth rates to be Markovian. We also deflate all nominal variables by the level of the relevant money supply. In particular, we let, $p\left(s^{t}\right)=$ $P\left(s^{t}\right) / M\left(s^{t}\right), w\left(s^{t}\right)=W\left(s^{t}\right) / M\left(s^{t}\right)$ as well as

$$
p_{i, z}\left(s^{t}\right)=\frac{P_{i, z}\left(s^{t}\right)}{M\left(s^{t}\right)}, p_{i, z}^{*}\left(s^{t}\right)=\frac{P_{i, z}^{*}\left(s^{t}\right)}{M^{*}\left(s^{t}\right)}, e\left(s^{t}\right)=\frac{E\left(s^{t}\right) M^{*}\left(s^{t}\right)}{M\left(s^{t}\right)}
$$

A stationary equilibrium for this economy consists of stationary decision rules and pricing rules that are functions of the state of the economy.

\section{Characterizing the Equilibrium}

Next we characterize the optimal decision rules of firms that reset their prices. The problem of such a firm in the home market is

$$
\max _{\left.P_{H i}\left(s^{t}\right)\right)} \sum_{r=t}^{\infty} \sum_{s^{r}} \lambda_{i}^{r-t} Q\left(s^{r} \mid s^{t}\right)\left[P_{H i}\left(s^{t}\right)\left(\frac{P_{H i}\left(s^{t}\right)}{P_{i}\left(s^{r}\right)}\right)^{-\gamma} c_{i}\left(s^{r}\right)-W\left(s^{r}\right)\left(\frac{P_{H i}\left(s^{t}\right)}{P_{i}\left(s^{r}\right)}\right)^{-\gamma} c_{i}\left(s^{r}\right)\right]
$$


The first order conditions (expressed in terms of deflated nominal variables) imply:

$$
\begin{aligned}
& \sum_{r=t}^{\infty} \sum_{s^{r}} \lambda_{i}^{r-t} Q\left(s^{r} \mid s^{t}\right)\left(\frac{p_{H i}\left(s^{t}\right)}{p\left(s^{r}\right) \mu\left(s^{r}, s^{t}\right)}\right)^{-\theta} c\left(s^{r}\right) \\
= & \frac{\theta}{\theta-1} \sum_{r=t}^{\infty} \sum_{s^{r}} \lambda_{i}^{r-t} Q\left(s^{r} \mid s^{t}\right) \frac{w\left(s^{r}\right)}{p\left(s^{r}\right)}\left(\frac{p_{H i}\left(s^{t}\right)}{p\left(s^{r}\right) \mu\left(s^{r}, s^{t}\right)}\right)^{-\theta-1} c\left(s^{r}\right) \\
= & \frac{\theta}{\theta-1} \sum_{r=t}^{\infty} \sum_{s^{r}} \lambda_{i}^{r-t} Q\left(s^{r} \mid s^{t}\right) \frac{w\left(s^{r}\right)}{p\left(s^{r}\right)}\left(\frac{p_{H i}\left(s^{t}\right)}{p\left(s^{r}\right) \mu\left(s^{r}, s^{t}\right)}\right)^{-\theta-1} c\left(s^{r}\right)
\end{aligned}
$$

Log-linearizing this expression around the steady-state gives

$$
\hat{p}_{H i}\left(s^{t}\right)=\left(1-\lambda_{i} \beta\right) \sum_{r=t}^{\infty} \sum_{s^{r}} \pi\left(s^{r} \mid s^{t}\right)\left(\lambda_{i} \beta\right)^{r-t}\left(\hat{w}\left(s^{r}\right)+\hat{\mu}\left(s^{t}, s^{r}\right)\right)
$$

which can be written recursively as

$$
\hat{p}_{H i}\left(s^{t}\right)=\lambda_{i} \beta \sum_{s^{r}} \pi\left(s^{t+1} \mid s^{t}\right) \hat{p}_{H i}\left(s^{t+1}\right)+\left(1-\lambda_{i} \beta\right) \hat{w}\left(s^{t}\right)
$$

where here and throughout we denote the log-deviation of a generic variable $x\left(s^{t}\right)$ from its steady-state by $\hat{x}\left(s^{t}\right)$.

A home firm that adjusts its dollar price therefore charges a price that is proportional to a weighted average of the firm's current marginal cost, $\hat{w}\left(s^{t}\right)$, and the price $\hat{p}_{H i}\left(s^{t+1}\right)$ it would set next period in each state $s^{t+1}$ if in that state it had a new opportunity to adjust. The weight the firm places on the future is proportional to the probability that the firm will not reset its price tomorrow, $\lambda_{i}$, as well as the discount factor.

A similar argument can be used to derive the optimal price of a foreign firm that resets its dollar price:

$$
\hat{p}_{F i}\left(s^{t}\right)=\left(1-\lambda_{i} \beta\right) \sum_{r=t}^{\infty} \sum_{s^{r}} \pi\left(s^{r} \mid s^{t}\right)\left(\lambda_{i} \beta\right)^{r-t}\left(\hat{e}\left(s^{r}\right)+\hat{w}^{*}\left(s^{r}\right)+\hat{\mu}\left(s^{t}, s^{r}\right)\right),
$$

which can be written recursively as 


$$
\hat{p}_{F i}\left(s^{t}\right)=\lambda_{i} \beta \sum_{s^{r}} \pi\left(s^{t+1} \mid s^{t}\right) \hat{p}_{F i}\left(s^{t+1}\right)+\left(1-\lambda_{i} \beta\right)\left(\hat{e}\left(s^{t}\right)+\hat{w}^{*}\left(s^{t}\right)\right)
$$

The dollar price of good $i$ sold in the home country can be written recursively as:

$$
\hat{p}_{i}\left(s^{t}\right)=\lambda_{i}\left(\hat{p}_{i}\left(s^{t-1}\right)-\hat{\mu}\left(s^{t}\right)\right)+\left(1-\lambda_{i}\right)\left(s \hat{p}_{H i}\left(s^{t}\right)+(1-s) \hat{p}_{F i}\left(s^{t}\right)\right)
$$

where $s=P_{H i}^{1-\theta} /\left(P_{H i}^{1-\theta}+P_{F i}^{1-\theta}\right)$ is the steady-state share of the home consumer's spending on home goods, equal to $s=1 /\left[1+(1+\tau)^{1-\theta}\right]$. To understand (14) let $\hat{p}_{i}^{N}\left(s^{t}\right)=s \hat{p}_{H i}\left(s^{t}\right)+$ $(1-s) \hat{p}_{F i}\left(s^{t}\right)$ denote the average newly-reset dollar price of good $i$ and then note that at $s^{t}$ there are the following measures of firms, $(1-\lambda)$ that have adjusted at $s^{t}$ and have average prices $\hat{p}_{i}^{N}\left(s^{t}\right), \lambda(1-\lambda)$ that have adjusted at $s^{t-1}$ and have prices $\hat{p}_{i}^{N}\left(s^{t-1}\right), \lambda^{2}(1-\lambda)$ that have adjusted at $s^{t-2}$ and have prices $\hat{p}_{i}^{N}\left(s^{t-1}\right)$. and so on. Thus, using (5) we can write

$$
\hat{p}_{i}\left(s^{t}\right)=(1-\lambda) \hat{p}_{i}^{N}\left(s^{t}\right)+\lambda(1-\lambda)\left(\hat{p}_{i}^{N}\left(s^{t-1}\right)-\hat{\mu}\left(s^{t}\right)\right)+\lambda^{2}(1-\lambda)\left(\hat{p}_{i}^{N}\left(s^{t-2}\right)-\hat{\mu}\left(s^{t}\right)-\hat{\mu}\left(s^{t-1}\right)\right)+\ldots
$$

which can be rewritten as (14).

Similar arguments can be used to derive that the evolution of the euro price of good $i$ sold in the foreign country is given by

$$
\hat{p}_{i}^{*}\left(s^{t}\right)=\lambda_{i}\left(\hat{p}_{i}^{*}\left(s^{t-1}\right)-\hat{\mu}^{*}\left(s^{t}\right)\right)+\left(1-\lambda_{i}\right)\left((1-s) \hat{p}_{H i}^{*}\left(s^{t}\right)+s \hat{p}_{F i}^{*}\left(s^{t}\right)\right)
$$

\section{The Relation between Price Stickiness and Sectoral Real Exchange Rates}

In this section we show that the standard sticky price model implies a tight link between the degree of price stickiness of a given sector and the persistence and volatility of that sector's real exchange rates. To build intuition we begin with a convenient parameterization that yields closed form solutions. We then show that the implications we develop hold more 
generally.

In the data nominal exchange rates are approximately random walks. We choose a parametrization so that the nominal exchange rate is a random walk in our model as well. We also choose a utility function that allows us to develop a closed-form $\mathrm{AR}(1)$ representation for the relative prices of goods across countries $q_{i}$.

We assume preferences are of the form

$$
U(c, l)=\log (c)-\psi l
$$

and that the (log of the) money supplies in the two countries are random walks $\left(\rho_{\mu}=0\right)$. To see that these preferences, or more generally any preferences of the form $\log c+V(l)$, imply that the nominal exchange rate follows a random walk notice that for such preferences the real exchange rate (11) reduces to

$$
q\left(s^{t}\right)=\kappa \frac{c\left(s^{t}\right)}{c^{*}\left(s^{t}\right)}
$$

which, assuming that the CIA constraint always binds, reduces to

(18) $E\left(s^{t}\right)=\kappa \frac{M\left(s^{t}\right)}{M^{*}\left(s^{t}\right)}$.

From (18) it is clear that if the money supplies follow random walks $\left(\rho_{\mu}=0\right)$ so does the nominal exchange rate so that

$$
\Delta \log E\left(s^{t}\right)=\hat{\varepsilon}_{\mu}\left(s^{t}\right)-\hat{\varepsilon}_{\mu}^{*}\left(s^{t}\right)
$$

Making the utility function linear in labor allows us closed form $\mathrm{AR}(1)$ representation for relative prices.

In the following proposition we show that sector by sector the half-life of the sectoral relative price equals the infrequency of price adjustment $\lambda_{i}$ for that sectorand that the as the 
following proposition shows.

Proposition 1. (Relating Real Exchange Rates and Price Stickiness) With a utility function of the form (16) and with random walk nominal exchange rates, the stochastic process governing the relative price $q_{i}\left(s^{t}\right)$ is of the form

$$
\hat{q}_{i}\left(s^{t}\right)=\lambda_{i} \hat{q}_{i}\left(s^{t-1}\right)+\eta\left(s^{t}\right)
$$

where $\eta_{i}\left(s^{t}\right)=\lambda_{i}\left(\hat{\varepsilon}_{\mu}\left(s^{t}\right)-\hat{\varepsilon}_{\mu}^{*}\left(s^{t}\right)\right)$ is an i.i.d. random variable with standard deviation $\sigma_{\eta}(i)=$ $2 \lambda_{i}^{2} \sigma_{\mu}^{2}$. Thus,

i) the half-life of the sectoral relative price equals the infrequency of price adjustment and

ii) the conditional variance of the sectoral relative price is proportional to the infrequency of price adjustment.

Proof. Using (18) it follows that $e\left(s^{t}\right)=\kappa$. Using the form of preferences (16), the labor supply first-order condition (6) reduces to

$$
W\left(s^{t}\right)=M\left(s^{t}\right) \text { or } w\left(s^{t}\right)=1 .
$$

Nominal wages in both countries are thus proportional to each country's money supply. Similarly, the nominal exchange rate is proportional to the ratio of the two country's money supplies. Thus, $\hat{w}\left(s^{t}\right)=\hat{w}^{*}\left(s^{t}\right)=\hat{e}\left(s^{t}\right)=0$. Adjusting firms therefore set a price that is proportional to the money supply of the country in which the good is sold so that

$$
\hat{p}_{H i}\left(s^{t}\right)=\hat{p}_{F i}\left(s^{t}\right)=0 \text {. }
$$

Substituting (21) into (14) and (15) implies that good $i$ 's relative price $q_{i}\left(s^{t}\right)=E\left(s^{t}\right) P_{i}^{*}\left(s^{t}\right) / P_{i}\left(s^{t}\right)$ 


$$
\hat{q}_{i}\left(s^{t}\right)=\lambda_{i} \hat{q}_{i}\left(s^{t-1}\right)+\lambda_{i}\left(\hat{\mu}\left(s^{t}\right)-\hat{\mu}^{*}\left(s^{t}\right)\right) .
$$

The result then follows. Q.E.D.

To help interpret this proposition, combine (19) and (20) to obtain

$$
\hat{q}_{i}\left(s^{t}\right)=\lambda_{i} \hat{q}_{i}\left(s^{t-1}\right)+\lambda_{i}\left(\Delta \log E\left(s^{t}\right)\right)
$$

Consider a sector that is relatively more sticky in that the good defining that sector has a relatively high infrequency of price adjustment $\lambda_{i}$. For such a good, a given innovation in the growth of nominal exchange rates leads to a relatively larger jump in the current sectoral real exchange rate because a relatively small fraction of firms in that sector are allowed to change their prices on impact. Over time when firms adjust they do so to offset the innovation to the nominal exchange rate. In a sector with relatively more sticky prices firms adjust less frequently and the half-life of the sectoral real exchange rate is lower. Finally, note that in the extreme case that firms never adjust their prices, the sectoral real exchange rate perfectly tracks the nominal exchange rate. That is, with $\lambda_{i}=1,(23)$ becomes $\Delta \hat{q}_{i}\left(s^{t}\right)=\Delta \log E\left(s^{t}\right)$.

We illustrate the implications of this proposition with a simple graph. In Figure 1 we plot the model's predictions for the response to a unit innovation in the nominal exchange rate for two goods: good 1 has relatively sticky prices $\left(\lambda_{1}=.95\right)$ and good 2 has relatively flexible prices $\left(\lambda_{1}=.50\right)$. As panel A shows, after the shock the price of the good 1 responds much more slowly than that of good 2. As panel B shows, the slower response of good 1 means that following an exchange rate innovation, the real exchange rate of good 1 both jumps more on impact and decays more slowly than that of good 2 .

What is going on at the firm level within the sectors producing these two goods is the following. At time $t$ a positive money shock at home causes the nominal exchange rate to depreciate on impact. Since money shocks follow a random walk the nominal exchange rate 
stays at its new depreciated level. In the sector producing good 1 , the relatively sticky sector, only $5 \%$ of firms get to change their prices on impact. Those $5 \%$ increase their prices to offset the depreciation but the other $95 \%$ of firms are stuck with their original prices. Hence, the price of the good in this sector, which is a weighted average of the prices of the individuals firms, moves little and the impact effect on the real exchange rate is large. In the next period $5 \%$ of firms again get to change their prices and the firms that do, change them to offset the money shock. So at the end of period $190 \%\left(.95^{2}\right)$ of firms are stuck with their original prices and about $10 \%(.05+.05 * 95)$ have changed either on impact or in period 1 . Over time, as the fraction of firms stuck with their original prices dwindles so does the resulting movement in the real exchange rate for this good. In the sector producing good 2, on impact $50 \%$ of firms immediately change their price to offset the change in exchange rate and the over time the fraction of firms that are stuck with their original price quickly dwindles. Hence, the real exchange rate for the relatively flexible price good jumps up less on impact and more quickly reverts to its mean than does the relatively sticky price good.

Note that this proposition implies that both the persistence and the standard deviation of innovations to real exchange rates are independent of the size of trade costs. In particular, even if the countries are not trading at all, goods whose prices are completely flexible $\left(\lambda_{i}=0\right)$ have constant relative prices across countries. Moreover, even if countries have no costs to trade, so that $s=1 / 2$, goods whose prices are completely inflexible $\left(\lambda_{i}=1\right)$ have relative prices that follow a random walk.

This tight link between the persistence and volatility of international relative prices and the frequency of price changes is not an artifact of our particular parametrization of preferences in the economy. To illustrate this point, we compute the serial correlation of the relative price $q_{i}$ as a function of the infrequency of price changes, $\lambda_{i}$ for alternative parameterizations. 
Consider first a utility function of the form

$$
U(c, l)=\frac{c^{1-\sigma}}{1-\sigma}+\psi \frac{(1-l)^{1-\delta}}{1-\delta}
$$

The relationship between the behavior of relative prices and the frequency of price changes is more complicated in this general formulation and depends on the details of the economy's calibration. We interpret a period as one month. We choose $\theta$, the elasticity of substitution across goods and $\gamma$ the elasticity of substitution across brands be 10, a choice that implies a markup of $11 \%$. We choose the trade cost $\tau$ so that the market share of home firms in home is $85 \%$. Finally, we choose the weight on leisure $\psi$ in the utility function so that the household allocates $1 / 3$ of its time to market activity.

Figure 2 plots the serial correlation of $q_{i}$ as a function of $\lambda_{i}$ for several choices of $\sigma$ and $\delta$. Even large departures from the example above lead to a similar positive relationship between the infrequency of price changes and the persistence of relative prices.

We also consider an additional class of preferences, popular in the business cycle literature, in which consumption and leisure are non-separable. Specifically we use

$$
U(c, l)=\frac{\left(c(1-l)^{\zeta}\right)^{1-\sigma}}{1-\sigma}
$$

with $\zeta=2.25$, a common formulation in the business cycle literature and $\sigma$ equal to 1 and 5. Figure 3 shows that a similar positive relation holds between the infrequency of price adjustment and the correlation of sectoral real exchange rates for these preferences as well.

\section{Data}

In our examination of the cross-section implications of the sticky price story for good (or sector) level real exchange rates we compare the degree of price stickiness with the volatility and persistence of good level (sector level) real exchange rates for US and several European countries. 
We work with two separate sources of disaggregated real exchange rates. The first source of data is the harmonized indices of consumer prices that available from Eurostat. This dataset is available from 1996 to 2006, and we work 66 product categories in this sample. The source of the US price data are the time-series available from the BLS. The second source is the Eurostat price data employed by Imbs. et. al (2005) in their study of the aggregation bias in real exchange rates and corresponds roughly to the two-digit level of disaggregation $^{1}$. Examples of product categories are bread, meat, dairy, furniture, domestic appliances etc. We use a total of 18 product categories (we exclude "rents" for which data on the degree of price stickiness is unavailable for most countries in our sample) for which monthly price series are available for 1981-1995.

The source of information regarding the degree of price stickiness across disaggregated product categories is several studies in which large datasets of price quotes collected at the level of individual outlets for the purpose of computing aggregate price indices have been subsequently employed in order to calculate the frequency of price adjustment for disaggregated product-categories. In particular, the source of U.S. data is Bils and Klenow (2005) for which data on the frequency of price adjustment is available for 350 different entry-level items. In addition to the U.S. data, we have had access to data for Austria for which Baumgartner et. al (2005) have computed data on the frequency of price adjustment for 639 product categories; Belgium: Aucremanne and Dhyne (2004) have computed data for 583 product categories; France: Baudry et. al (2006) have provided us with data for 136 product categories; as well as Spain: statistics for 61 product categories computed by Alvarez and Hernando (2004). These data are available in the above-mentioned sources, or have been graciously supplied to us by the authors of these studies. ${ }^{2}$

To get a feel for how this frequency of price adjustment is computed consider the example from Bils and Klenow (2004 p. 949). In their dataset there were 6493 quotes for bananas in 1997 and of these $37.8 \%$ differed from the quote for the same type of banana at the same outlet in the preceding month. The implied frequency of price changes in 1997 is 
then $37.8 \%$ per month. Bils and Klenow report implied frequencies for each of their product categories averaged over a three year period. The studies that we use for European countries use an approach analogous to that used by Bils and Klenow. These studies also define price changes in a similar manner as do Bils and Klenow, in that they have a similar treatment of temporary price cuts, product replacements, temporary stockouts, and so on. For example, all studies, with the exception of Spain, include temporary price cuts (sales) in their definition of a price change. Similarly, price changes due to product replacement are counted as price changes in all studies, except for Belgium. In all instances, the price quotes underlying these statistics were collected during three or more years of the 1990s. (For details see our technical appendix.)

These statistics on the frequency of price changes are available, in most instances, at a finer level of disaggregation than the sectoral price data from Eurostat. We therefore aggregate these statistics using consumption expenditure weights provided to us by the authors of the respective studies. We have manually merged these different sources of data, using the United Nations classifications registry, as well as the BLS classification definitions available in the BLS Handbook of Methods. In most instances the match is fairly unambiguous for all products we use.

Let $f_{i j}$ be the frequency of price adjustment for sub-category $i$ of product $j$ in a particular country. Here $j$ refers to the product categories (either 66 or 18) for which Eurostat price data is available, while $i$ refers to the disaggregated components for which the frequency of price adjustment is available. For example, one of the 66 goods for which we have price data is $i=$ "Fish and Seafood". For the United States, Bils and Klenow (2005) report frequencies of price adjustment for sub-categories $j=\{$ "Canned Fish or Seafood", "Shellfish (excl canned)", "Fish (excl. canned).\}. We compute a single statistics for "Fish and Seafood" using $^{3}$

$$
f_{i}=\sum_{j \in i} w_{i j} f_{i j}
$$


A final issue is that of product coverage. Data on the frequency of price changes is only available for only a subset of goods that make up each of the 66 categories we work with. The US data is fairly complete, as the only missing products in the Bils and Klenow (2005) data are owner's equivalent rent and insurance, residential housing, and used cars. Thus, the only product category for which coverage is incomplete is COICOP 0711 (Motor Cars): $72 \%$ of this category is covered by the Bils and Klenow data, the rest is "used cars". We compute similar coverage ratios for all other countries in our sample. We do so by dividing the sum of the weights of all goods that belong to a particular product category for which data on the frequency of price adjustment is available, by the total consumption expenditure weight on that category. Our technical appendix discusses the concordance between the different datasets and other data issues in detail and presents coverage ratios for each good and country. We only work with those goods for which the data on the frequency of price changes covers at least $50 \%$ of that good's total consumption expenditure.

Table 1 presents the mean (across $i=1, \ldots, 66$ ) of the fraction of prices that change in a particular month for each country in our larger sample, as well as the correlation of $f_{i}$ for each of the four European countries with the US. Although prices in US are substantially more flexible (26\% of prices change in a particular month on average) than those in the four European countries (the frequency of price changes ranges from 14\% in France to $19 \%$ in Spain), the cross-country correlations of $f_{i}$ are large (greater than 60\%) in all countries. Goods that are at the flexible-end of the spectrum in US (fruits \& vegetables, fuels and lubricants) tend to adjust frequently in all countries. Similarly, goods whose prices are relatively sticky in US (services) are also characterized by relatively infrequent price changes in Europe. ${ }^{4}$

\section{Evidence}

The sticky price model we have investigated implies a stark relation between the stickiness of prices and the persistence and volatility of disaggregated real exchange rates. As Proposition 1 illustrates the serial correlation of sectoral real exchange rates, as well as the variance of innovations to the real exchange rate process are proportional to the infrequency 
of price adjustment $\lambda_{i}$, the probability that the firm does not adjust its price in a particular period.

Our empirical measure of the infrequency of price adjustment $\lambda_{i}$ in the data is $1-f_{i}$, that is, the proportion of prices in a particular sector that do not experience a price change in a particular month. Our measure of persistence of the real exchange rate in in sector $i$, namely $\rho_{i}$, is obtained from a regression of the form $\hat{q}_{i t}=\rho_{i} \hat{q}_{i t-1}+\varepsilon_{i t}$. The volatility of innovations, $\sigma_{i}$, is measured as the standard deviation of the residuals in this same regression. We normalized this volatility by dividing by the standard deviation of the changes in the log of the nominal exchange rates, $\sigma_{\Delta e}$, since in the theory this normalized volatility $\sigma_{i} / \sigma_{\Delta e}$ equals $\lambda_{i}$. (We also ran regressions of the form and experimented with including monthly dummies and time trends. See the Appendix for details.)

The panels of Figure 4 plot for each of our four countries the real exchange rate persistence, $\rho_{i}$, against the infrequency of price adjustment, $\lambda_{i}$, for each good. We also draw on the prediction of the model (namely that the persistence equals the infrequence of price adjustment) and an OLS regression line of our measured real exchange rates on our measure infrequencies of price adjustment. The theory predicts that relatively sticky goods (those with high $\lambda_{i}$ ) should have relatively higher persistence (high $\rho_{i}$ ). That qualitative pattern clearly holds in the data.

The problem for the theory is quantitative. It predicts a one-for-one relation between $\lambda_{i}$ and $\rho_{i}$, in that $\rho_{i}=\lambda_{i}$. In the data, however, even though prices range from fairly flexible to fairly sticky the real exchange rates are all fairly persistent. Hence, in the data the real exchange rate persistence is a much flatter function of the infrequency of price adjustment than the theory dictates.

A couple of examples can help put this feature in perspective. In the Belgian data the most flexibly priced good is fuels (more precisely, fuels and lubricants for personal transport equipment). Consider first expressing the discrepancy between the theory and the data for this good in terms of half-lives. The infrequency of price adjustment for fuels is about .3 
(.296). The theory predicts that the half-life of the real exchange rate for fuels should be about a half a month (.57 months). In the data the serial correlation of the real exchange rate for fuels is .962 which corresponds to a half life of almost 18 months (17.84). In short, the actual half life for the real exchange rate for fuels is over 30 times that predicted by the theory.

We can express this same discrepancy in terms of durations of price spells. For the theory to generate the observed persistence of the real exchange rate for fuels, the duration of price spells for fuels would need to be over 26 months. The actual duration of price spells for fuels is only about one and a half months. Expressed either way, we would need substantially more stickiness in the price of fuel for our theory to predict as persistent a real exchange rate for fuels as we see in the data.

The discrepancy for the most sticky goods is far smaller. In the Belgian data one of the stickiest goods is cleaning (actually, cleaning, repair and hire of clothing). It has an infrequency of price adjustment of .952. The theory predicts that the half life of the real exchange rate for cleaning should be about 14 months. The actual half life is about 18 months (17.75). In terms of durations for the theory to generate the observed perisistence of the real exchange rate for cleaning we would need price spells to last about 26 months, while in the data they last for only 21 months.

Consider the second cross section implication of the sticky price model, namely that for each good, the normalized volatility of innovations of the good-level real exchange rate $\left(\sigma_{i} / \sigma_{\Delta e}\right)$ should equal the infrequency of price adjustment $\left(\lambda_{i}\right)$. Figure 5 plots these two series against each other. In the data we see while the model predicts a positive relation between these series the data shows a negative relation. The intutition for this prediction is from Figure 1. For any given exchange rate shock (generated from an underlying innovation in money), the less sticky a good is the more its price moves to offset the shock and hence the less volatile is the resulting real exchange rate. What is going on at the firm level in a sector with infrequency parameter $\lambda_{i}$ is that on impact $1-\lambda_{i}$ fraction of firms in that sector 
adjust their prices

We summarize some of the results from Figures 4 and 5 in Table 2. The correlation of the persistence for good level real exchange rates in the data with that predicted by the model is .43 on average across countries. The half life of real exchange rates in the data 33.8 months, computed as an average of the median across countries, is substantially higher than the half-life predicted by the model, 3.5 months.

Finally, we also wanted to compare the (unconditional) volatility of real exchange rates predicted by the theory relative to those in the data. To do so we computed the standard deviation of real exchange rates predicted by the theory, $q_{i t}^{T}$, to that in the data, $q_{i t}^{D}$. To do so we constructed the real exchange rate predicted by the theory for this sample using

$$
q_{i t}^{T}=\lambda_{i} q_{i t-1}^{T}+\lambda_{i}\left(\Delta \log E_{t}^{D}\right)
$$

where the initial real exchange rate $q_{i 0}^{T}$ is set to that in the data $q_{i 0}^{D}$ and then computed the standard deviation of $q_{i t}^{T}$ relative to the standard deviation of $q_{i t}^{D}$. In Table 2 we report the weighted median of these standard deviations for each of the countries. Across countries the average fraction of volatility the real exchange rates that the theory can account for is $32 \%$.

There is a simple way to see what it is about the raw data that leads to the discrepancies we have documented between the model and the data. In Figure 6a we plot the average of the real exchange rates for the 3 least sticky goods in the Belgian data, the average of the real exchange rates for the 3 most sticky goods in the Belgian data together with the nominal exchange rate ${ }^{5}$. Clearly, all 3 series move closely together. It is this pattern in the raw data that drives all of our results. In Figure $6 \mathrm{~b}$ we plot the average of the real exchange rates for the 3 most sticky goods and the corresponding average predicted by the theory. In Figure $6 c$ we do the same for the 3 least sticky goods. As we can see, for the most sticky goods the theory does reasonably well, but for the least sticky goods, the theory implies a much less volatile and much less persistent path of real exchange rates than is in the data. 


\section{Adding Pricing Complementarities.}

A possible complaint with our benchmark model is that it abstracts from forces that are thought to increase the endogenous stickiness of prices for some given frequency of exogenous price adjustment. The idea with pricing complementarities is to make the producer of any given product to have an incentive to price in a similar manner to other firms in the economy.

A simple way to introduce pricing complementarities is to introduce intermediate goods, so that all firms use as inputs a composite of other firms's output. For notational simplicity consider a generic firm but suppress the good and variety index for that firm and simply write its production function for gross output as

$$
y\left(s^{t}\right)=m\left(s^{t}\right)^{\alpha} l\left(s^{t}\right)^{1-\alpha}
$$

where $m\left(s^{t}\right)$ are intermediate inputs purchased from all firms $(i, z)$. Here the input purchased by the firm is a composite of the inputs from each sector $i$ given by

$$
m\left(s^{t}\right)=\left(\int_{0}^{1} m_{i}\left(s^{t}\right)^{\frac{\theta-1}{\theta}} d i\right)^{\frac{\theta}{\theta-1}}
$$

and the composite input from sector $i$ is itself composed of the varieties $z$ within that sector.

$$
m_{i}\left(s^{t}\right)=\left(\int_{0}^{1} m_{i z}\left(s^{t}\right)^{\frac{\gamma-1}{\gamma}} d i\right)^{\frac{\gamma}{\gamma-1}} .
$$

The parameter $\alpha \in[0,1]$ denotes the share of intermediate inputs in gross output. Now for each firm the marginal cost of producing an extra unit depends not only on the wage rate for labor but also on the prices charged by all other firms. The idea behind pricing complementarities is that it makes prices across firms move more closely together and it leads price stickiness to, in some sense, spill over from one firm to another.

To see how this mechanism works consider a shock to money (and hence exchange rates) in period $t$ and consider a firm that is allowed to change its price in period $t$. The 
firms sets its price based on its beliefs about expected future nominal marginal cost. When $\alpha=0$ this future nominal cost is just the nominal wage, as in equation (13). When $\alpha>0$ part of this future nominal cost is the price charged by other firms for their output. Thus, even though this particular firm can change its price, many of the firms it is buying inputs from cannot (and will be allowed to only over time) this firm raises its price by less than it otherwise would have with $\alpha=0$.

We illustrate this implication of the model for an extreme degree of complementarities by making $\alpha=.99^{6}$. In Figure 7 we plot the impulse responses to a home money shock for a relatively sticky sector with $\lambda=.95$ and a relatively flexible sector with $\lambda=.5$ in a model with $\alpha=.99$ and the frequency of price adjustment across firms set as we measure it in the Austrian data. Now compare Figure 7 to its the analogous Figure 1 for the (which can be thought of as the pricing complementarity model with $\alpha=0$ ). We see that these complementarities only slightly reduce the speed of adjustment for prices for the relatively sticky sector but that the greatly reduce the speed of adjustment of prices for the relatively flexible sector. Thus the complementarities increase the persistence of the real exchange rate for the relatively flexible sector more than they do for the relatively sticky sector. At a qualitative level at least, such a modification of the theory should then move the theory in the direction of the data.

In Figures 8 and 9 and Table 3 we report on the analog of Figures 4 and 5 and Table 2 for the model with extreme pricing complementarities. A brief perusal of these figures and tables shows that whileadding complementarities moves the theory in the right direction the theory it is still fairly far from the data. For example, comparing Tables 2 and 3 we see that adding complementarities on average across goods and countries increases the model's predicted half-life for real exchange rates from 4.5 months to 8 months while the analogous half-life in the data is nearly 34 months. Adding complementarities also increases the fraction of volatility of real exchange rates that the theory can account for from $32 \%$ to $45 \%$.

To get a feel for what is happening to individual goods consider again the predictions 
of the model for the least sticky goods in Belgium, fuel, and one of the most sticky goods in Belgium, cleaning. Adding complementarities raises the model's predicted half life for fuels from about a half a month to 5.3 months. While that is a substantial increase it is still well short of the half-life of fuels of 18 months implied by the data. For cleaning, adding complementarities raises the model's predicted half-life for the real exchang rate from 14 months to 16.5 months which is fairly close to that 17.5 months implied by the data.

Finally, in Figures 10a and 10b we graph the average of the real exchange rates for the 3 most sticky and the 3 least sticky goods in the Belgian data against the corresponding averages implied by the theory. Comparing these figures to Figures $6 \mathrm{~b}$ and $6 \mathrm{c}$ we see that for both sets of goods the theory is now somewhat closer to the data. Nonetheless, for the least sticky goods, the theory still implies a much less volatile and much less persistent path of real exchange rates than is in the data.

\section{Conclusion}

We have used panel data to examine some stark implications of the classic theory for real exchange rates. This data provides, at best, modest support for the sticky price theory. We argue that the quantitative discrepancies between the theory and the data are of such a magnitude that they should be a major focus of atttention for economists interested in using sticky price models to analyse business cycles. 


\section{Appendix: Data and Sources}

We work at the (roughly) 4-digit $\mathrm{COICOP}^{7}$ disaggregation level: a maximum of 66 products for which disaggregated CPI data is available together with statistics on the frequency of price changes, although for some countries the number of products is reduced due to lack of CPI series or information on the frequency of price changes. At this point, we have data available for US, as well as 4 European countries: Austria, Belgium, France, Spain.

\section{A. Disaggregated Consumer Prices: Seasonally Unadjusted}

US: Bureau of Labor Statistics ftp://ftp.bls.gov/pub/time.series/cu/), cu.data.0.current Europe: Eurostat: Harmonized indices of consumer prices - Monthly data (index 2005=100)

In addition to the raw CPI data, we also need, for several products, CPI weights associated with particular product categories that we can use in order to aggregate price indices for combinations of product categories for which CPI data is not immediately available from the above sources, e.g., "Fruits and Vegetables."

The source of these weights is:

\begin{tabular}{l|l|l} 
CEX survey & Reference Period & Years covered \\
\hline $1993-95$ & December 1997 & $1996-2001$ \\
\hline $1999-00$ & December 2001 & $2002-2003$ \\
\hline $2001-02$ & December 2003 & $2004-2005$ \\
\hline $2003-04$ & December 2005 & $2006-$
\end{tabular}

Eurostat: Harmonized indices of consumer prices - Item weights

We depart from the BLS methodology slightly in computing aggregated price indices for years 1996-1997. For these years BLS uses the 1982-1984 CEX survey to compute weights and these differ, in several instances, sharply from those introduced in 1998, which causes spurious movements in the computed price index. Moreover, the item structure was revised 
in 1997, and matching categories pre and after the revision is difficult. We therefore use December 1997 as a reference period when computing the 1996-1997 weights.

For Eurostat, the reference period is each December from 1996 onwards.

To compute an aggregate price index for a particular combination of sub-indices, we use a formula employed by the BLS to compute aggregate price indices. (See, e.g., page 37 in Chapter 17 of the BLS Handbook of Methods, Eurostat follows a similar approach to compute price indices for all member states, although individual countries differ in their own methodologies).

$$
P_{t}=P_{\beta_{t}} \frac{\sum_{i} w_{\beta_{t}}^{i} P_{\alpha, t}^{i}}{\sum_{i} w_{\beta_{t}}^{i} P_{\alpha, \beta_{t}}^{i}}
$$

where $i$ is an index over the sub-categories used to compute a particular index (e.g., $i=$ $\left\{\right.$ Fruits, Vegetables), $\beta_{t}$ is the weight reference period (the December prior to the year the weights are updated), $\alpha$ is the base period of the elementary index (December 1997 for US, January 2006 for Eurostat, these dates are chosen because all sub-indices needed are available in these periods), $P_{\alpha, t}^{i}$ is the lower-level index of price changes from period $\alpha$ to month $t$ for sub-index $i$. The formula above is a Laspeyeres index with fixed weights during a particular year: $\sum_{i} w_{\beta_{t}} P_{\alpha, t}^{i}$, re-referenced to the level of prices in each period in which weights are changed: $\frac{P_{\beta_{t}}}{\sum_{i} w_{\beta_{t}} P_{\alpha, \beta_{t}}^{i}}$. This correction smooths out fluctuations in the price index that arise due to changes in weights from one reference period to another, as $P_{\beta_{t}}$ is a weighted average of $P_{\alpha, \beta_{t}}^{i}$, with the previous weights. In practice these correction terms have a very minor effect on the CPI series.

No weights are available for US category "motor oil, coolant, and fluids",series SS47021 which we need to merge with "Motor Fuel" to construct the equivalent of COICOP 0722 "Fuels and lubricants for personal transport equipment". We use instead the share of ELI 47021 (Motor Oil) in the 1995 CEX (available from Bils and Klenow (2005)(0.045\%) relative to that of all expenditure on fuel (3.18\%) and multiply by the year-specific weight on "Motor 
Fuel"in the "Relative importance" data available from BLS.

The same is true for CPI series SS31022 "Video cassettes and discs, blank and prerecorded", for which weights are not available. We impute these by multiplying the weight of SS31022 to the sum of weights of SS31022 (.084\%) and SS62055 (Rental of video tapes and discs) (.26\%) and multiplying by the year-specific weight of "Video cassettes, discs, and other media including rental", available in the "Relative importance" tables.

Also, SS61023 has a weight of 0.48 in ELI 61021,61022,61023 (film, photographic and darkroom supplies, photographic equipment). CPI weights are available only for Photographic equipment and supplies which combines them all. We impute the relative weight of SS61023 by multiplying 0.48 by the weight on Photographic equipment and supplies for each year. The relative weight of SS61021 is (1- .48) times the same year-specific weights.

\section{B. Frequency (and Size) of Price Changes}

US: Bils and Klenow (2005),

data for 350 Entry Level Items available in the Appendix.

Austria: See Baumgartner, Glatzer, Rumler and Stiglbauer (2005) for a description of the data. The authors have shared with us statistics for 639 product categories that are not reported in the paper.

Belgium: Aucremanne and Dhyne (2004).

Data for 583 product categories available in the paper. The authors have shared with us CPI weights associated with each product category.

France: Baudry, Le Bihan, Sevestre, Tarrieu (2006).

The authors have shared with us statistics for 136 5-digit COICOP categories that are not reported in the paper. 
Spain: Alvarez and Hernando (2004).

Data for 61 product categories is available in the paper. The authors have shared with us the CPI weights associated with each product category ${ }^{8}$.

For all countries, a frequency (cross-sectional) approach is used to measure the degree of price stickiness. That is, instead of using the duration of price spells directly (an approach made difficult by the relatively short span of data, as well as censoring), the data we use is the average (across time-periods) fraction of prices (in a particular product category) changed within the course of any given month.

The studies above differ somewhat in the methodology used to define a price change, treatment of sales, product replacements, stockouts etc, as well as the sample size, periods covered etc. The table below summarizes the key differences. 


\begin{tabular}{|c|c|c|c|c|c|}
\hline & US & Austria & Spain & Belgium & France \\
\hline years covered & $95-97$ & $96-03$ & $93-01$ & 89-01 & $94-03$ \\
\hline \% CPI covered & $69 \%$ & $80 \%$ & $70 \%$ & $68 \%$ & $65 \%$ \\
\hline Include sales? & Yes & Yes & No & Yes & Yes \\
\hline $\begin{array}{l}\text { Include return to a different } \\
\text { regular price following a sale }\end{array}$ & $\mathrm{N} / \mathrm{A}$ & $\mathrm{N} / \mathrm{A}$ & $?$ & $\mathrm{~N} / \mathrm{A}$ & $\mathrm{N} / \mathrm{A}$ \\
\hline $\begin{array}{l}\text { Include price changes } \\
\text { due to product replacement? }\end{array}$ & Yes & Yes & Yes & No & Yes \\
\hline $\begin{array}{l}\text { Include price changes } \\
\text { after stockout? }\end{array}$ & Yes & Yes & $?$ & Yes & Yes \\
\hline $\begin{array}{l}\text { Include changes after } \\
\text { seasonal unavailability? }\end{array}$ & Yes & No & $?$ & No & No \\
\hline
\end{tabular}

The statistics in all these datasets are available, in most cases, at a finer level of disaggregation than the Eurostat CPI data. We therefore aggregate these statistics (more on this below) using those consumption expenditure weights used by the authors of the abovementioned studies. E.g., for US, these come from the 1995 CEX, for Spain these are the 1992 CPI weights, etc.

Aggregating statistics for 4-digit COICOP aggregates is straightforward for European countries, where the narrower product categories correspond to a finer COICOP disaggregation (although, in some cases the COICOP classifications differ because of the different 
vintages). For the match between US ELIs and COICOP categories, see the sub-section below. The one difficulty arises in case of the Spanish data, where the level of aggregation is sometimes coarser than that for which CPI data for Eurostat is available. We are therefore forced to throw out observations on "Books" and "Newspaper and Periodicals:" the Spanish study only reports statistics for "Books, Newspapers and Magazines", as well as "Electricity" and "Gas": data for "Electricity and Gas" is only available in the Spanish dataset.

\section{Concordance Tables}

We need to match the US CPI data available from the BLS, as well as the Bils-Klenow frequencies of price adjustment, available for 350 entry-level-items with the 4-digit COICOP categories. We have merged these different source of data manually, using United Nations COICOP classification registry available at

http://unstats.un.org/unsd/cr/registry/regcs.asp?Cl $=5 \& \mathrm{Lg}=1 \& \mathrm{Co}=01.1$, as well as the BLS classification available in the CPI Appendix 6, Chapter 17 of the BLS Handbook of methods.

In most instances the match is fairly disambiguous. (See Table 1 at the end of this document). In several cases we have had to merge several 4-digit COICOP categories into 1. For example, Fruits and Vegetables form one category, as BLS does not provide CPI data for Fruits and Vegetables separately.

Several matches are somewhat ambiguous:

1. Eurostat's COICOP 032 (Footwear including repair) is matched with BLS' SEAE (Footwear) which does not include repairs. The share of spending on shoe repairs is however less than $1 \%$ of the total spending on footwear in the 1995 CEX, so the discrepancy is small.

2. Eurostat's COICOP 0712_0713_0714 (Motorcycles, bicycles, and animal drawn vehicles) is matched with BLS' SS45031 (new motorcycles). Here the match is less perfect as expenditure on bicycles is $1 / 2$ that on motorcycles in the $1995 \mathrm{CEX}$. 
3. COICOP 1231 (Jewelry, Clocks and Watches) is matched with BLS' SEAG (Jewelry and Watches). Clocks account however for less than $2 \%$ of the spending on Jewelry, Clocks and Watches. Also, COICOP 1231 includes repairs, whereas the US category does not.

In all these cases, when merging the other datasets (e.g., Bils and Klenow's (2005) statistics), the COICOP coverage of a good takes precedence. For example, even though the US price series that corresponds to Eurostat's COICOP 0712_0713_0714 (Motorcycles, bicycles, and animal drawn vehicles) is SS45031 (new motorcycles), we include the frequency of price adjustment for bicycles in computing the relevant measures of price stickiness for this particular product category.

\section{Coverage Ratios}

Data on the frequency of price changes is only available for a subset of goods that make up each of the 66 categories we work with. The US data is fairly complete, as the only missing products in the Bils and Klenow (2005) category are owner's equivalent rent and insurance, residential housing, and used cars. Thus, the only product category for which coverage is incomplete is COICOP 0711 (Motor Cars): $72 \%$ of this category is covered by the Bils and Klenow data, the rest is used cars.

We compute similar coverage ratios for all other countries in our sample. We do so by dividing the sum of the weights of all goods that belong to a particular product category for which data on the frequency of price adjustment is available, by the total consumption expenditure weight on that category. The source of the consumption expenditure weight in the denominator is as follows (see Table 2 for these coverage ratios):

Belgium: Aucremanne and Dhyne use an average of the 1981, 1988, 1996 consumption expenditure weights to compute expenditure weights for the 583 products in their data. We only have 1996 weights available for the 66 aggregated categories we consider (available from Eurostat, these are the same weights as those used to aggregated lower-level CPI indices that are discussed above), and this is what we use as a denominator (unless weights for 1996 are 
missing, in which case we use the next available year). Note that some ratios are greater than 1, reflecting changes over time in the consumption weight on a particular product: the numerator is an average over 1981, 1988, 1996, whereas the denominator uses only 1996 data, and to the extent to which the share of a product decreases from 1981 to 1996, the coverage ratio we compute is greater than 1 .

Austria: We use the CPI basket weights for 2000 in the denominator to calculate a coverage ratio. This is the year in which Statistics Austria has redefined the consumption basket. The data was made available to us by Fabio Rumler. Again, some weights are greater than 1, as the numerator is an average of the 1996 and 2000 weights.

Spain. We use the CPI basket weights for 1992, the same as those used by Alvarez and Hernando (2004). In this case the match is perfect as same set of weights are used in the numerator and denominator.

France: the weights in the numerator were computed by the authors using an average of the 1993-2003 CPI weights. We therefore use an average of the 1996-2003 weights in the denominator.

\section{E. Nominal Exchange Rates}

Available from the St. Louis Fred: EXAUUS, EXBEUS, etc. Starting with 1999, the Euro-USD (EXUSEU) exchange rate is used instead. To render pre and post 1999 rates comparable, country exchange rates are converted to Euro at the "fixed euro conversion rates" available at http://www.ecb.int/bc/intro/html/index.en.html 


\section{Notes}

${ }^{1}$ We use the version of the data Helene Rey provides on her webpage. This data is revised version of the data used in Imbs et al. (2005) that incoporates the changes made by Chen and Engel (200?) as well as additional changes made by Imbs et al. (2006) to account of measurement problems in the original Eurostat data.

${ }^{2} \mathrm{We}$ are indebted to the authors of the above-mentioned studies, and in particular to Emmanuel Dhyne, Fabio Rumler, Herve Le Bihan and Luis Alvarez for supplying us with some of the data used in this study as well as for clarifying a number of methodological issues.

${ }^{3}$ An alternative approach would be to use $f_{i}=\left(\sum_{i \in j} w_{i j} \frac{1}{f_{i j}}\right)^{-1}$ which is the inverse of a weighted average of the impled durations $1 / f_{i j}$. Because $1 / f$ is convex in $f$, Jensen's inequality implies that this alternative approach would lead to a smaller estimate of the frequency of price adjustment than the one we used. All our results below are very similar across these two approaches to aggregation, a result indicative of the fact that within-sector heterogeneity is much less pronounced than heterogeneity in the frequency of price adjustment across sectors.

${ }^{4}$ We refer the reader to Dhyne et. al (2005) for an exhaustive comparison of the pricesetting behavior in US and Europe.

${ }^{5}$ The least sticky goods are fuels and lubricants for personal transport equipment; liquid and solid fules; and fruits and vegetables, with durations of .57 months, .79 months, and .91 months respectively. The most sticky goods are hairdressing salons and personal grooming establishments; restaurants, cafes, and canteens; and miscellaneous printed matter, stationary and drawing materials with durations of 23 months, 15 months, and 12 months respectively.

${ }^{6}$ Note that our value of $\alpha$ is well beyond the already extreme range of .85 to .9 argued for by Woodford 2003 p. 173

${ }^{7}$ Classification of Individual Consumption by Purpose.

${ }^{8}$ with the data as well as for the answering many methodological questions we have had. 


\section{References}

BETTS, C., and DEverEuX, M. B. (2000), "Exchange Rate Dynamics in a Model of Pricing-to-Market", Journal of International Economics, 50, 215-244.

CALVO, G. A. (1983), "Staggered Prices in a Utility-Maximizing Framework", Journal of Monetary Economics, 12, 383-398.

CHARI, V. V.; KEHOE, P. J.; and MCGRATTAN, E. R. (1998), "Can Sticky Price Models Generate Volatile and Persistent Real Exchange Rates?" Review of Economic Studies.

DIXIT, A. K., and STIGLITZ, J. E. (1977), "Monopolistic Competition and Optimum Product Diversity", American Economic Review,67, 297-308.

DORNBUSCH, R. (1976), "Expectations and Exchange Rate Dynamics", Journal of Political Economy, 84, 1161-1176.

FLEMING, J. M. (1962), "Domestic Financial Policies Under Fixed and Under Floating Exchange Rates" International Monetary Fund Staff Papers 9, pp[ 369-379.

HANSEN, G.D. (1985), "Indivisible Labor and the Business Cycle" Journal of Monetary Economics, November 1985, v. 16, iss. 3, pp. 309-27.

KRUGMAN, P. R. (1987), "Pricing to Market When the Exchange Rate Changes", in S. W. Arndt and J. D. Richardson (eds.), Real-Financial Linkages Among Open Economies, pp. 49-70 (Cambridge, Mass.: MIT Press).

MARSTON, R. C. (1990), "Pricing to Market in Japanese Manufacturing", Journal of International Economics, 29, 217-236.

MUNDELL, R. A. (1963), "Capital Mobility and Stabilization Policy Under Fixed and Flexible Exchange Rates, " Candian Journal of Economics and Political Science 29, pp. 475-485.

MUSSA, M. (1986), "Nominal Exchange Rate Regimes and the Behavior of Real Exchange Rates: Evidence and Implications", Carnegie-Rochester Conference Series on Public Policy, 25, 117-213.

OBSTFELD, M., and ROGOFF, K. (1995), "Exchange Rate Dynamics Redux", Journal of 
Political Economy,103, 624-660.

ROGERSON, R. (1988), "Indivisible Labor, Lotteries and Equilibrium Rogerson", Journal of Monetary Economics, January 1988, v. 21, iss. 1, pp. 3-16.

SVENSSON, L. E. O., and VAN WIJNBERGEN, S. (1989), "Excess Capacity, Monopolistic Competition, and International Transmission of Monetary Disturbances", Economic Journal, 99, 785-805. 